
Kopi

\title{
SENSOR INFRARED BERBASIS TEKNOLOGI TEPAT GUNA PADA THERMOS PENUANG MINUMAN KOPI
}

\author{
Widodo $^{1)}$ dan Agus Ridwan ${ }^{2)}$ \\ ${ }^{1)}$ Program Studi Teknik Elektro, Fakultas Teknologi Industri \\ ${ }^{2)}$ Program Studi Pendidikan Kesejahteraan Keluarga, Fakultas Keguruan dan Ilmu Pendidikan \\ Universitas PGRI Adi Buana Surabaya \\ Email : widodo.adibuana@gmail.com
}

\begin{abstract}
Abstrak
Untuk memudahkan penyelesaian pekerjaan rumah tangga maka perlu adanya alat bantu yang diharapkan bisa lebih praktis dan lebih efisien. Misalnya dengan menggunakan peralatan rumah tangga yang serba otomatis. Sebagai contoh : rice cooker, alat memasak serba guna, dispenser, mixer dan lain-lain yang mendukung teknologi baru, murah, dan tidak dibutuhkan tenaga pembantu rumah tangga yang semakin mahal dan sulit didapatkan. Peneliti mencoba membuat peralatan yang lebih praktis dengan melakukan desain ulang peralatan yang ada. Peralatan tersebut adalah alat penuang kopi yang sebelumnya masih menggunakan sistem konvensional dalam menuangkan kopi. Sistem kerja peralatan ini dapat menuangkan kopi ke cangkir dengan dimensi yang telah ditentukan secara otomatis tanpa menekan tombol. Volume kopi yang dituangkan dapat otomatis sesuai volume yang dikehendaki. Peralatan ini menggunakan sensor yang didesain untuk dapat bekerja otomatis mendeteksi cangkir kopi yang diletakkan pada posisi tertentu yang selanjutnya akan diisi dengan minuman kopi. Volume kopi yang dituangkan menngunakan perhitungan debit aliran air. Untuk mendapatkan volume penuangan kopi yang sesuai maka dilakukan pengaturan waktu. Dari hasil penelitian yang telah dilakukan, didapatkan bahwa penggunaan sistem kerja peralatan ini lebih praktis dibanding sistem konvensional. Karena pada sistem otomatis, volume kopi yang dituangkan pada cangkir dapat diatur dan secara otomatis berhenti sesuai volume yang kita inginkan.
\end{abstract}

Kata Kunci : Sensor Infrared, Teknologi Tepat Guna, Thermos

\begin{abstract}
To facilitate the completion of household chores then the need for a tool that is expected to be more practical and more efficient. For example, by using household appliances fully automated. For example: rice cooker, versatile cooking appliance, dispensers, mixers and others who support the new technology, cheap, and no power is needed housekeeper increasingly expensive and difficult to obtain. Researchers tried to make the equipment more practical to do the redesign of existing equipment. The equipment is pouring coffee tools that previously were using the conventional system in pouring coffee. This equipment working systems can pour a cup of coffee with a predetermined dimension automatically without pressing the button. Coffee being poured volumes can be automated according to the volume that we want. This equipment uses sensors that are designed to work automatically detect the coffee cups were placed in a particular position which would then be filled with a coffee drink. Poured coffee volume calculation using a flow of water. To obtain the appropriate volume of coffee pouring it done setting the time. From the research that has been done, it was found that the use of work equipment system is more practical than conventional systems. Because of the automated system, the volume of coffee being poured in the cup can be set and automatically stops according to the volume we want.
\end{abstract}

Keyword : Infrared sensors, Appropriate Technology, Thermos 


\section{PENDAHULUAN}

Pada era perubahan jaman dan perkembangannnya yang semakin pesat, menuntut manusia bekerja keras agar dapat mencukupi kebutuhan hidup yang semakin kompleks. Emansipasi kaum wanita lebih memilih berkarir pada perusahaan atau berwira usaha daripada sebagai ibu rumah tangga yang hanya mengurusi pekerjaan rumah. Oleh karenanya untuk memudahkan penyelesaian pekerjaan rumah tangga, didesain peralatan yang lebih praktis dan lebih efisien, yaitu dengan peralatan rumah tangga yang serba otomatis. Sebagai contoh : rice cooker, alat memasak serba guna, dispenser, mixer dan lain-lain yang mendukung teknologi baru, murah, dan tidak dibutuhkan tenaga pembantu rumah tangga yang semakin mahal dan sulit didapatkan.

Berdasarkan alasan diatas, dicoba menuangkan suatu gagasan untuk merangkai peralatan rumah tangga yang praktis, ekonomis, dan otomatis yaitu alat penuang kopi secara otomatis. Keunggulan alat ini adalah tanpa memerlukan orang penuang kopi dalam gelas. Minuman kopi yang tertuang dalam gelas tidak akan tumpah atau meluber. Petugas hanya mengisi kembali apabila termos sudah kosong. Selain itu komponen-komponen yang dipergunakan untuk merancang alat, mudah didapat di pasaran dengan harga relatif terjangkau. Dengan menggunakan beberapa komponen sensor yang berfungsi sebagai pendeteksi gelas, sensor pendeteksi bekerja sesuai dengan fungsinya yaitu mencapai volume minuman kopi yang telah ditentukan. Permasalahan yang dirumuskan adalah bagaimanakah merancang dan membuat thermos penuang minuman kopi yang bekerja secara otomatis.Tujuan penelitian ini adalah mengembangkan model alat penuang minuman kopi yang sudah ada di pasaran dengan model yang lebih ekonomis dan praktis, mengaplikasikan sensor-sensor yang tepat serta untuk menumbuhkan kreativitas penggemar elektronika yang menghasilkan teknologi tepat guna.

\section{METODE}

\section{Metode Penelitian}

Penelitian yang dilakukan adalah penelitian pengembangan yang bertujuan untuk menemukan dan mengembangkan prototype baru atau sudah ada dalam rangka penyempurnaan dan pengembangan sehingga diperoleh hasil yang lebih produktif, praktis, efektif dan efisien (Benny Kurniawan, 2012).

\section{Tahapan Penelitian}

Desain penelitian alat penuang kopi otomatis ini didasari oleh ide alat penuang minuman kopi di pasaran selanjutnya kami kembangkan agar lebih praktis, efektif dan efisien dengan memanfaatkan switch sensor infra merah secara maksimal. Adapun tahapan-tahapan penelitian ini adalah seperti pada gambar berikut:

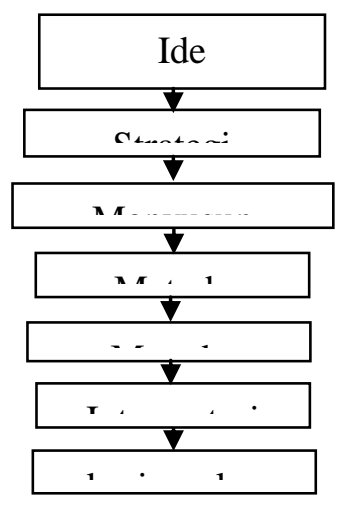

Gambar 1. Tahapan Penelitian

\section{Lokasi Penelitian}

Untuk merancang dan merangkai komponen-komponen elektronika serta melakukan pengujian, pengukuran dan percobaan alat penuang minuman kopi otomatis berbasis switch infra merah dilakukan di Laboratorium Teknik Elektro Universitas PGRI Adi Buana Surabaya di gedung Sardjijo, Jl.Dukuh Menanggal XII Surabaya, yang membutuhkan waktu 4 bulan.

\section{Rancangan Penelitian}

Rancangan Penelitian yang dituangkan seperti pada gambar 2. dibawah ini : 


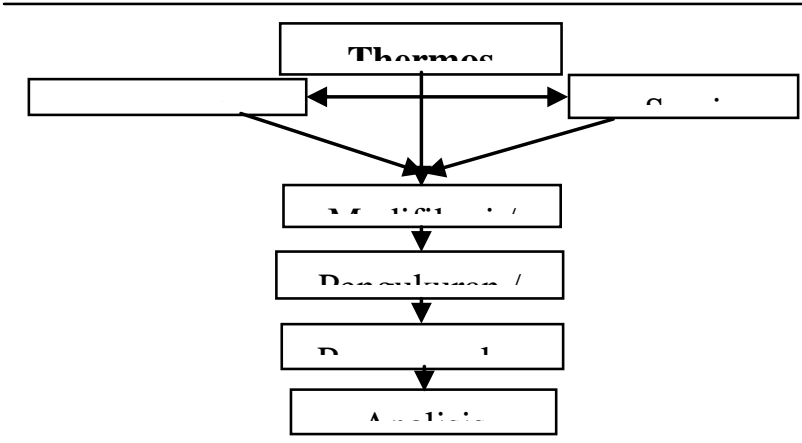

Gambar 2. Rancangan Penelitian

\section{Rancangan Alat}

Kondisi sensor pada saat belum ada gelas pada ruang gelas seperti pada gambar 3 dan gambar 4 merupakan sensor pada saat gelas dimasukkan ke ruang gelas berikut.

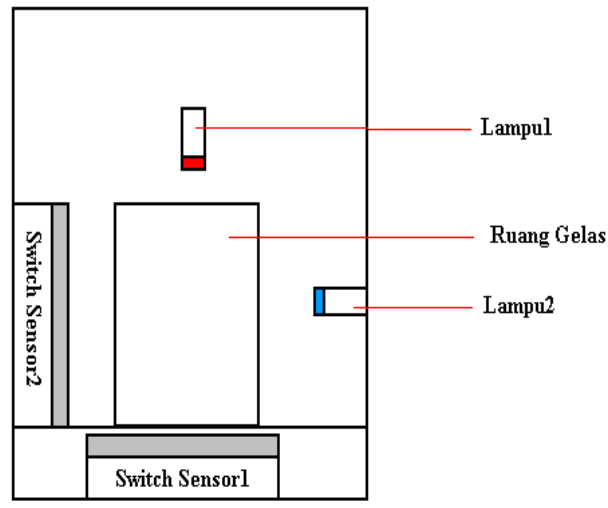

Gambar 3. Kondisi sensor sebelum ada gelas

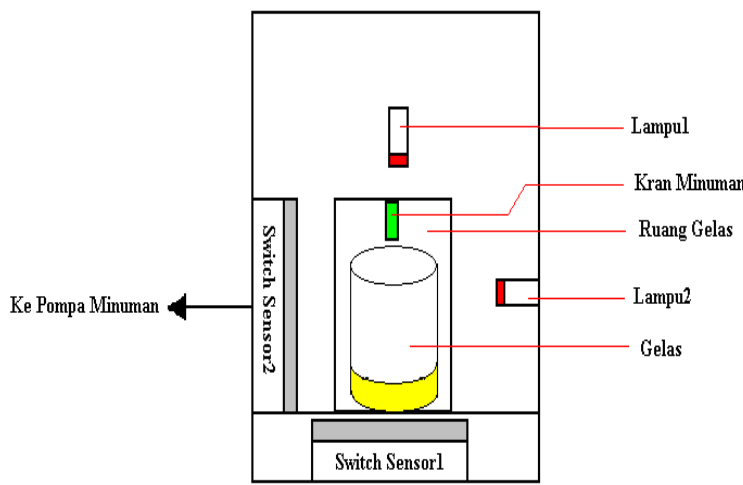

Gambar 4. Kondisi sensor setelah ada gelas
Kondisi sensor saat menghidupkan pompa minuman seperti pada gambar 5 .

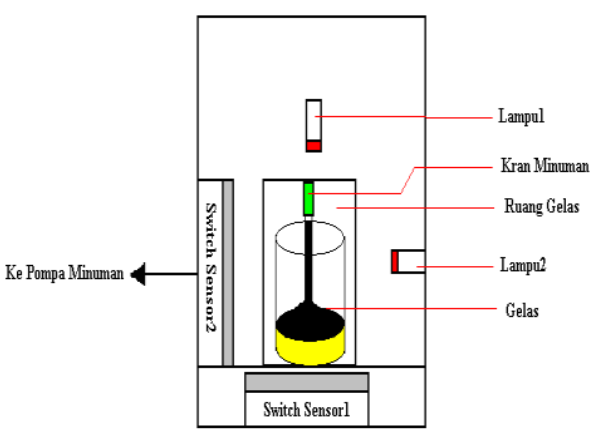

Gambar 5. Kondisi sensor saat menghidupkan pompa minuman

Kondisi sensor pada saat kopi mulai penuh

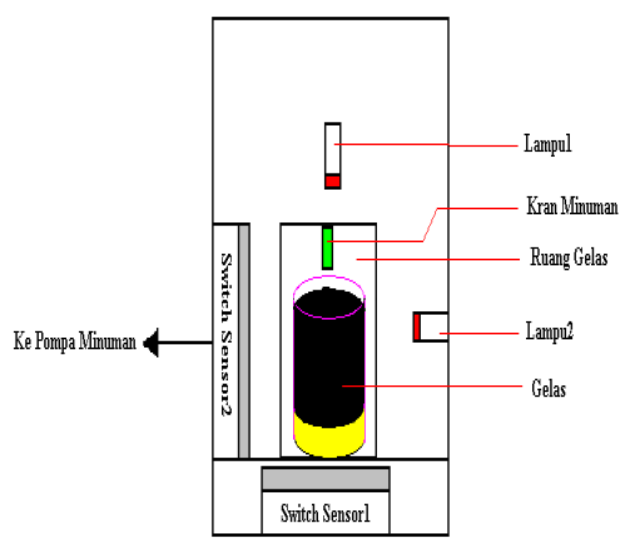

Gambar 6. Kondisi sensor saat kopi mulai penuh 

Kopi

\section{Teknik Pengumpulan dan Analisis Data}

Teknik pengumpulan data yang dipakai adalah:

a. observasi : pengamatan dan pencatatan datadata hasil uji laboratorium

b. literatur : rancangan didasari oleh teori-teori yang relevan

Analisis yang digunakan adalah analisis uji laboratorium yaitu untuk mengukur variabel yang telah ditetapkan sebagai tujuan akhir.

\section{Analisis data}

Analisis data yang digunakan adalah analisis uji laboratorium. Yaitu melakukan pengukuran komponen-komponen yang akan dirakit harus sesuai dengan keluaran yang diharapkan, meliputi karakter sensor, spesifikasi solenoid valve, timer, dan komponen pendukung lain yang perlu dihitung nilainya sebelum dipasang. Hasil uji coba sensor didapatkan bahwa sensor hanya dapat mendeteksi cangkir dengan dimensi tertentu. Jadi untuk obyek yang tidak memenuhi kriteria tersebut maka sensor tidak bekerja dan proses penuangan tidak terjadi, hal ini dimaksudkan untuk tujuan keamanan.

\section{HASIL DAN PEMBAHASAN}

Penelitian yang dilakukan adalah penelitian pengembangan yaitu melakukan modifikasi dari thermos minuman kopi yang biasa digunakan melalui penekanan manual apabila menuangkan minuman kopi maupun teh dikembangkan dengan penambahan sensor dan komponen lain sehingga untuk menuangkan air kopi atau teh cukup diletakkan sedemikian rupa sensor dapat membaca gelas yang diletakkan dan secara otomatis air keluar dengan sendirinya dengan jumlah voleme yang telah diatur sebelumnya.

\section{Komponen yang digunakan}

1. Sensor Infra merah

2. Kran elektrik / Solenoid valve

3. Pengukur waktu / timer

4. Power supply

\section{Thermos yang dihasilkan}

Dalam penelitian ini mengambil experimen dari penuang kopi otomatis, pengertian dari penuang kopi adalah suatu alat yang berfungsi memudahkan menuangkan kopi ke dalam gelas. Gambar penuang kopi yang sederhana, dimana pengoprasiannya masih menggunakan sistem manual. Dari contoh alat penuang kopi diatas masih membutuhkan beberapa pemodifikasian sehingga dapat menjadi alat yang berfungsi sebagai teknologi tepat guna sehingga didapat aspek otomatisasi agar dapat berfungsi secara praktis efisien dan hemat energi

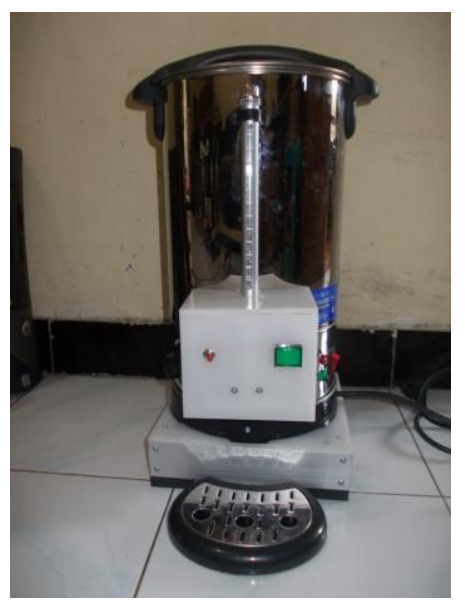

Gambar 7. Thermos penuang minuman otomatis

\section{Data hasil pengukuran}

Pengukuran yang dilakukan adalah pengukuran:

1. Ketepatan pendeteksian sensor

Karakteristik dari sensor adalah sebagai berikut:

Jarak maksimum pengukuran objek adalah sekitar $13 \mathrm{~cm}$. dan lebar pendeteksian obyek pengukuran adalah maksimum pada jarak $8-10$ $\mathrm{cm}$ sebesar $4 \mathrm{~cm}$. dengan grafik sebagai berikut:

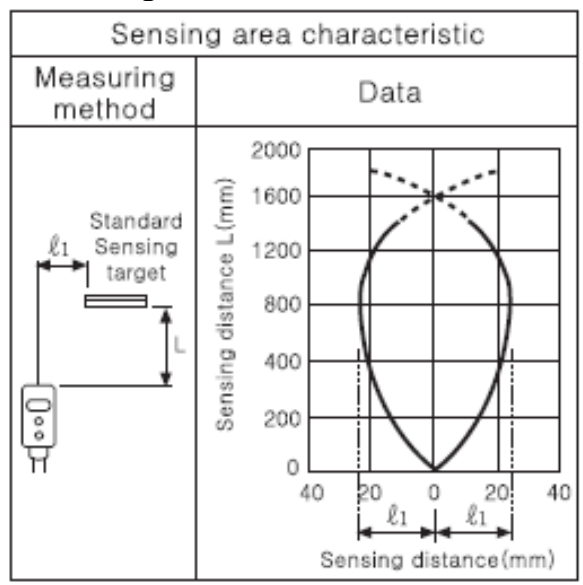

Gambar 8. Grafik pendeteksian sensor

Cahaya infra merah merupakan cahaya yang tidak tampak. Jika dilihat dengan 
spektroskop cahaya maka radiasi cahaya infra merah akan terlihat pada spektrum elektromagnet dengan panjang gelombang di atas panjang gelombang cahaya merah. Radiasi inframerah memiliki panjang gelombang antara $700 \mathrm{~nm}$ sampai $1 \mathrm{~mm}$ dan berada pada spektrum berwarna merah. Dengan panjang gelombang ini maka cahaya infra merah tidak akan terlihat oleh mata namun radiasi panas yang ditimbulkannya masih dapat dirasakan/dideteksi.

Pada dasarnya komponen yang menghasilkan panas juga menghasilkan radiasi infra merah termasuk tubuh manusia maupun tubuh binatang. Cahaya infra merah, walaupun mempunyai panjang gelombang yang sangat panjang tetap tidak dapat menembus bahanbahan yang tidak dapat melewatkan cahaya yang nampak sehingga cahaya infra merah tetap mempunyai karakteristik seperti halnya cahaya yang nampak oleh mata.

Pada pembuatan komponen yang dikhususkan untuk penerima infra merah, lubang untuk menerima cahaya (window) sudah dibuat khusus sehingga dapat mengurangi interferensi dari cahaya non-infra merah. Oleh sebab itu sensor infra merah yang baik biasanya memiliki jendela (pelapis yang terbuat dari silikon) berwarna biru tua keunguunguan. Sensor ini biasanya digunakan untuk aplikasi infra merah yang digunakan diluar rumah (outdoor).

Sinar infra merah yang dipancarkan oleh pemancar infra merah tentunya mempunyai aturan tertentu agar data yang dipancarkan dapat diterima dengan baik pada penerima. Oleh karena itu baik di pengirim infra merah maupun penerima infra merah harus mempunyai aturan yang sama dalam mentransmisikan (bagian pengirim) dan menerima sinyal tersebut kemudian mendekodekannya kembali menjadi data biner (bagian penerima). Komponen yang dapat menerima infra merah ini merupakan komponen yang peka cahaya yang dapat berupa dioda (photodioda) atau transistor (phototransistor). Komponen ini akan merubah energi cahaya, dalam hal ini energi cahaya infra merah, menjadi pulsa-pulsa sinyal listrik. Komponen ini harus mampu mengumpulkan sinyal infra merah sebanyak mungkin sehingga pulsa-pulsa sinyal listrik yang dihasilkan kualitasnya cukup baik.
2. Volume pengisian minuman pada cangkir

Volume pengisian dihitung dari pengukuran debit aliran dan waktu yang dibutuhkan untuk mendapatkan volume pengisian minuman pada cangkir.

Dari pengukuran didapatkan bahwa untuk proses penuangan pada cangkir membutuhkan waktu 4 detik dengan volume $180 \mathrm{ml}$. jadi debit air dapat dihitung sebagai berikut:

Debit $=$ Volume $:$ Waktu

Debit $=180 \mathrm{ml}: 4$ detik

Debit $=45 \mathrm{ml} /$ detik

Switching otomatis adalah rangkaian yang bersifat otomatis yang sistem kerjanya tanpa melibatkan tangan manusia, tetapi dengan media terprogram terlebih dahulu dengan tujuan meringankan pekerjaan. Switching sendiri terdiri dari berbagai macam bentuk serta desain yang bervariasi yang disesuaikan dengan kebutuhan dan kegunaan. Dalam dunia elektronika switching di bagi menjadi dua macam yaitu :

1. Switching manual

Switching manual yaitu switch yang berfungsi atau bekerja dengan perantara manusia atau benda lain. Suatu contoh saklar lampu, saklar televisi

2. Switching otomatis

Switching otomatis yaitu switcing yang bekerja secara otomatis tanpa adanya bantuan manusia tetapi dengan media alam, suatu contoh pengukur suhu, pengukur cuaca dan lain sebagainya. Switching ini banyak sekali didesain untuk memudahkan manusia itu sendiri dan dengan beragam bentuk serta desain yang bervariasi sesuai dengan kebutuhan dan kegunaan. Rangkaian switching ini pasti ada pada tiap-tiap rangkaian elektronik baik yang menggunakan sistim digital maupun analog. komponen penyusun rangkaian switching.

a. Relay

Relay adalah suatu komponen elektronika yang terdiri dari lilitan dan swicth manual yang bekerja dengan lilitan tersebut. Dengan adanya arus yang masuk pada lilitan relay maka akan timbul gaya magnet sehingga menarik atau membuka swicth. 

Kopi

Menurut FRANK D. PETRUZELLA (2001: 371) Relay pengendali elektro mekanis adalah saklar magnetis. Relay ini menghubungkan rangkaian beban on atau off dengan pemberian energi elektromagnetis yang membuka dan menutup kontak pada rangkaian. EMR mempunyai variasi aplikasi yang luas baik pada rangkaian listrik maupun elektronis.

Relay hanya memiliki satu kumparan, tetapi relay dapat mepunyai beberapa kontak. Kontak ditunjukkan sebagai normally open (NO) dan normally close (NC) dengan sistim kerja sebagai berikut :

1. Kontak normally open akan membuka ketika tidak ada arus mengalir pada kumparan, dan akan tertutup secepatnya setelah kumparan menghantarkan arus atau diberi tenaga.

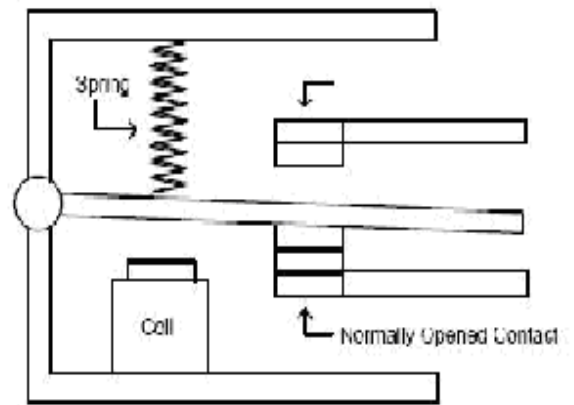

Gambar 9. Kontak Normally Open

2. Kontak normally close akan tertutup apabila kumparan tidak diberi arus dan membuka ketika kumparan diberi arus, dan akan terbuka secepatnya setelah kumparan menghantarkan arus atau diberi tenaga.

b. Resistor

Resistor atau tahanan adalah salah satu komponen elektronika yang berfungsi untuk penghambat arus listrik, memperkecil arus listrik dan membagi arus listrik dalam suatu rangkaian

1. Resistor Tetap

2. Resistor Tidak Tetap

3. Resistor Tidak Tetap Otomatis

c. Kondensator kondensator ialah jenis komponen elektronika yang sifatnya dapat menyimpan tenaga listrik selama kurun waktu yang di tentukan tanpa disertai reaksi kimia.kondensator mempunyai nama lain yang kadang-kadang orang menyebutnya kapasitor. Sedikitdikitnya kondensator ini mepunyai 2 bagian plat logam yang terpisah oleh bantuan bahan isolasi. Bahan isolasi ini disebut dielektrikum. Kondensator ini jenisnya banyak, diantaranya adalah sebagai berikut :

1. kondensator keramik

2. kondensator mika

3. kondensator elektrolit

4. kondensator udara

5. kondensator polyster

\section{Data hasil pengamatan}

Dari hasil pengamatan didapatkan bahwa kerja sensor hanya dapat mendeteksi cangkir dengan dimensi tertentu yaitu :

Diamater cangkir $=7-8.5 \mathrm{~cm}$

Ketinggian cangkir $=5-8 \mathrm{~cm}$.

\section{KESIMPULAN}

Telah dilakukan redesain dari alat penuang minuman dengan memodifikasi sistem manual menjadi otomatis. Dari hasil penelitian ini dapat disimpulkan sebagai berikut:

1. Alat hasil desain ulang sudah berhasil bekerja sesuai dengan tujuan. Yakni bekerja otomatis menuang minuman.

2. Sensor inframerah yang digunakan untuk mendeteksi obyek berupa cangkir mempunyai karakteristrik tertentu berdasarkan pengukuran dimensi, hal ini untuk tujuan keamanan karena volume penuangan disesuaikan dengan volume cangkir.

\section{Ucapan Terimakasih}

Penelitian ini telah mendapatkan dukungan dari Lembaga Penelitian dan Pengabdian pada Masyarakat Universitas PGRI Adi Buana (UNIPA) Surabaya yang telah membantu dalam bidang pendanaan penelitian dan juga laboratorium Teknik Elektro UNIPA Surabaya. 
Widodo \& Agus Ridwan : sensor Infrared Berbasis Teknologi Tepat Guna Pada Thermos Penuang Minuman Kopi

\section{DAFTAR PUSTAKA}

Arikunto, Suharsimi 2001, Prosedur Penelitian. Yogyakarta : PT. Rineka Cipta.

AT, Sobirin .2003 Teori dan Praktek Programmable Logic control. PT. Bukaka teknik Utama ,Bogor Jawa Barat

Malik, Ibnu Moch. 2006. Pengantar Membuat robot. Yogyakarta : Gava Media.

Petruzella, D, Frank. 2001. Elektronik Industri. Yogyakarta: ANDI OFFSET.

Roefi'ie, M. 1997. Mesin DC Motor. Surabaya: U-Press IKIP.

Setiawan, Iwan. 2005. Programmable Logic Controller (PLC) Dan Teknik Perancangan Sistem Kontrol. Yogyakarta: ANDI OFFSET.

Suhendar. 2005. Programmable Logic Controller (PLC) Edisi Pertama. Yogyakarta: Graha Ilmu. 